Check for updates

Cite this: RSC Adv., 2018, 8, 194

Received 3rd November 2017

Accepted 14th December 2017

DOI: $10.1039 / c 7 r a 12101 f$

rsc.li/rsc-advances

\title{
Synthesis and properties of soluble aromatic polyimides from novel 4,5-diazafluorene- containing dianhydride
}

\author{
Bo Deng, ${ }^{a}$ Shujiang Zhang, ${ }^{\text {ab }}$ Chang Liu, ${ }^{a}$ Wei Li, ${ }^{a}$ Xiangdong Zhang, ${ }^{a}$ Hua Wei ${ }^{a}$ \\ and Chenliang Gong (iD *abc
}

A series of organo-soluble, high glass transition temperature $\left(T_{\mathrm{g}}\right)$, and low dielectric constant aromatic polyimides containing 4,5-diazafluorene in the polymer chain were synthesized from a novel dianhydride monomer, 9,9-di[4-(3,4-dicarboxyphenoxy)phenyl]-4,5-diazafluorene dianhydride. The introduction of 4,5-diazafluorene units improved the solubility of aromatic polyimides in commonly used organic solvents, and even in dichloromethane, 1,4-dioxane and tetrahydrofuran. The obtained polyimide films also exhibited excellent thermal stability with $T_{\mathrm{g}}$ between $270{ }^{\circ} \mathrm{C}$ and $311{ }^{\circ} \mathrm{C}$, and decomposition temperatures at $10 \%$ weight loss $\left(T_{10 \%}\right)$ between $493{ }^{\circ} \mathrm{C}$ and $552{ }^{\circ} \mathrm{C}$. Moreover, the 4,5 -diazafluorenecontaining polyimides showed low dielectric constant located between 2.78 and 3.38, good mechanical properties with tensile strength between 92 and $105 \mathrm{MPa}$ and elongations at break in the range of 4.49$24.8 \%$.

\section{Introduction}

As one kind of high performance polymer, aromatic polyimides (PIs) have been applied in many high-tech fields such as aerospace, ${ }^{1}$ gas separation, ${ }^{2,3}$ memory devices, ${ }^{4,5}$ and the microelectronics industry, ${ }^{6,7}$ because of their excellent thermal and oxidative stabilities, high mechanical strength and flexibility, and good dielectric properties. However, the rigid structure, strong inter-molecular interactions and charge transfer complex (CTC) of aromatic polyimides always lead to their poor solution processability and dark brownish colour, limiting their application in many areas. $^{\mathbf{8 - 1 1}}$ Generally, polyimides are synthesized by the polycondensation of diamine and dianhydride. Many approaches focused on structure modification (novel diamine and dianhydride), such as introducing aliphatic chains, ${ }^{12,13}$ flexible linkage, ${ }^{\mathbf{1 4 - 1 6}}$ nonplanar structure, ${ }^{\mathbf{1 7 - 2 0}}$ bulky $\mathrm{CF}_{3}$ groups $^{21-23}$ and ring-shaped structures, ${ }^{24}$ are developed to overcome the traditional PIs' drawbacks mentioned above. However, in most of the case, as the solubility and transmittance of PIs improved, the thermal properties and mechanical properties are sacrificed.

${ }^{a}$ State Key Laboratory of Applied Organic Chemistry, College of Chemistry and Chemical Engineering, Lanzhou University, Lanzhou 730000, P. R. China. E-mail: gongchl@lzu.edu.cn

${ }^{b}$ Key Laboratory of Special Function Materials and Structure Design of Ministry of Education, Lanzhou University, Lanzhou 730000, P. R. China

${ }^{c}$ Key Laboratory for Polymeric Composite and Functional Materials of Ministry of Education, School of Chemistry and Chemical Engineering, Sun Yat-sen University, Guangzhou 510275, P. R. China
Instead of the traditional modification methods for PI property improvement, polyimide containing spirobifluorene has begun to be studied and exhibited excellent thermal stability, ${ }^{17,25}$ dielectrical properties,${ }^{26}$ solution processability, ${ }^{26,27}$ and high transparency. ${ }^{28-30}$ Such spiro structures twist at an angle of $90^{\circ}$ in the polymer chain which can reduce the close packing of the polymer chains, weaken the inter-chain interactions, and consequently result in better polymer solubility. On the other hand, the spirobifluorene units in polymer can improve their thermal stability and refractive indices because of the high content of aromatic units. Additional study indicated that the introduction of pyridine ring in the main chain of polyimide contributed to the improvement of PIs' solubility, oxidative stability, optical properties and thermal stability. ${ }^{31-37}$ The protonation of the lone pair electrons on the nitrogen atom can increase the solubility of the resulting polyimide in polar solvents. Moreover, the molar refractive index of the pyridine ring is higher than that of the benzene ring, thus it is helpful to enhance the refractive index and transmittance of the polyimide. ${ }^{34}$

In light of above observations and in consideration of the structure of diazafluorene in which the biphenyl structure of fluorene is replaced by a rigid planar bipyridine can combine the spiro aromatic structure and polar pyridine units, the diazafluorene-containing polyimides are expected to exhibit outstanding thermal stability, organo-solubility, refractive index and light transmission properties. In our previous study, we have synthesized a series of novel diamine monomers containing diazafluorene structures. The obtained polyimides exhibited improved solubility, $T_{\mathrm{g}}$ and thermal stability 
compared with the state-of-the-art PIs. ${ }^{38,39}$ Base on the above research, we anticipated that the introduction of diazafluorene unit in dianhydride could improve the reactivity of the monomer because of the high conjugated system and strong electron acceptor. Notably, the two non-coplanar pyridine rings of diazafluorene can increase the molar refractive index, reduce the form of CTC and the optical loss, disturb the orderly arrangement of the main chain, thereby improving the refractive index and transmittance of polyimides. ${ }^{34-41}$ However, because the synthesis of traditional dianhydride usually has complicated process and low yield in comparison with that of diamine, the relationships between structure and properties of dianhydride containing diazafluorene and the corresponding PIs have not yet been reported.

In this study, a new dianhydride monomer, namely 9,9-di[4-(3,43,4-dicarboxyphenoxy)phenylene]-4,5-diazafluorenedianhydride, has been synthesized, and polymerized with four different aromatic diamines. The thermal stability, solubility, refractive index and dielectric constant of the obtained polyimides are fully discussed in this article.

\section{Experimental}

\subsection{Materials}

9,9-Di(4-hydroxyphenyl)-4,5-diazafluorene was synthesized according to the previous literature. ${ }^{38}$ Anhydrous potassium carbonate, 4-fluorophthalonitrile, glacial acetic acid, acetonitrile, $N, N$-dimethylacetamide (DMAc), deuterated dimethyl sulfoxide (DMSO- $\mathrm{d}_{6}$ ) and acetic anhydride were purchased from Aladdin chemical. N,N-Dimethylformamide (DMF), $N$-methylpyrrolidone (NMP) and toluene were purified via distillation under negative pressure and stored over $4 \AA$ molecular sieves. Bis[4-(aminophenoxy)4-phenyl]isopropylidene, bis[4(aminophenoxy)4-phenyl]hexafluoroisopropylidene, 2,2'-bis[4(6-amino-3-pyridinoxy)phenyl]hexafluoropropane, and 4,4'-oxybisbenzenamine were prepared by known literature. ${ }^{34,41}$

\subsection{Characterizations}

Molecular weights were tested via gel permeation chromatography (GPC) using HPLC-grade DMF containing $0.1 \mathrm{wt} \% \mathrm{LiBr}$ at $60{ }^{\circ} \mathrm{C}$ as the eluent at a flow rate of $1 \mathrm{~mL} \mathrm{~min}^{-1}$. Tosoh TSK-GEL R-3000 and R-4000 columns (Tosoh Bioscience, Montgomeryville, PA, USA) were connected in series to an Agilent 1260 series (Agilent Technologies, Santa Clara, CA, USA), an interferometric refractometer (Optilab-rEX, Wyatt Technology, Santa Barbara, CA, USA) and a MALLS device (DAWN EOS, Wyatt Technology, Santa Barbara, CA, USA). The MALLS detector was operated at a laser wavelength of $690.0 \mathrm{~nm}$. NMR measurements were carried out using a Bruker 400 NMR spectrometer with tetramethylsilane (TMS) as internal standard and DMSO- $\mathrm{d}_{6}$ as a solvent. Elemental analyses were carried out using a Yanaco MT-6 CHN recorder elemental analysis instrument. Fourier transform infrared (FT-IR) spectra of the powder samples and the films were performed on a Nicolet NEXUS670 FT-IR spectrometer. A Hitachi U-3210 spectrophotometer was used to measure the ultraviolet-visible (UV-vis) spectra. Thermo gravimetric analysis (TGA) was measured with a TA Instruments TGA 2050 to test the thermal stability of the PIs, and the measurements was completed at a heating rate of $20{ }^{\circ} \mathrm{C} \mathrm{min} \mathrm{m}^{-1}$ from $50{ }^{\circ} \mathrm{C}$ to $800{ }^{\circ} \mathrm{C}$. Measurements of $T_{\mathrm{g}} \mathrm{s}$ and the storage modulus were analyzed by dynamic mechanical thermal analyses (DMA) using a Mettler Toledo DMA/SDTA861e instrument in film tension mode at a heating rate of $1^{\circ} \mathrm{C} \min ^{-1}$ from $35^{\circ} \mathrm{C}$ to $350{ }^{\circ} \mathrm{C}$ with a load frequency of $1 \mathrm{~Hz}$, a strain of $0.1 \mu \mathrm{m}$ and a stress of $0.1 \mathrm{~N}$. The elongation and tensile strength of the membranes were measured using a Universal Testing Machine (AGS-X 5 KN, Shimadzu, Japan) with a stretching speed of $1 \mathrm{~mm} \mathrm{~min}^{-1}$ at room temperature. The dielectric property of the films were characterized using a Solartron SI 1260 impedance/gain phase analyzer at frequencies from $100 \mathrm{~Hz}$ to $1 \mathrm{MHz}$ at $20^{\circ} \mathrm{C}$ and $50 \%$ relative humidity. The measurements were carried out at a dry chamber. A D8 Avance Bruker AXS diffractometer was used to measure wide-angle X-ray diffraction (XRD) at $25{ }^{\circ} \mathrm{C}$. A Gaertner L116B spectroscopic ellipsometer was used to measure the refractive index of films. Tensile properties were carried out using a Toyo Instron UTM-III-500 at a crosshead speed of $5 \mathrm{~cm} \mathrm{~min}^{-1}$. The weighting of changes in vacuum-dried film specimens before and after immersion in distilled water at room temperature for one day determined the water absorption. Solubility was tested with a $10 \mathrm{mg}$ sample in $1 \mathrm{~mL}$ solvent at $25{ }^{\circ} \mathrm{C}$.

\subsection{Synthesis of monomers and polyimides}

2.3.1 9,9-Di [4-(3,4-dicyano)phenyl]-4,5-diazofluorene (a). A mixture of 9,9-di-(4-hydroxyphenyl)-4,5-diazafluorene (10 mmol, $3.52 \mathrm{~g})$, anhydrous potassium carbonate $(13 \mathrm{mmol}$, $1.749 \mathrm{~g}$ ), 4-fluorophthalonitrile (22 mmol, $3.252 \mathrm{~g}$ ), $\mathrm{N}, \mathrm{N}$-dimethylformamide $(10 \mathrm{~mL})$ and toluene $(3 \mathrm{~mL})$ were stirred at $25{ }^{\circ} \mathrm{C}$ for 30 minutes. Then the solution was heated and refluxed for $10 \mathrm{~h}$ at $80^{\circ} \mathrm{C}$. The mixture was poured into $200 \mathrm{~mL}$ of ice water to give the raw product. The product was filtered and washed with distilled water. The crude product was recrystallized from acetonitrile/water (1:5 vol/vol) to give a white solid yield of $4.23 \mathrm{~g}(70 \%)$.

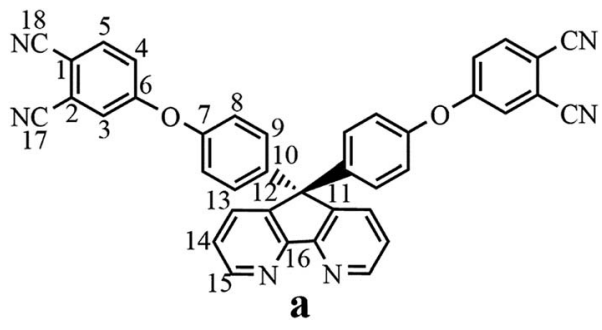

FT-IR (KBr, $\left.v, \mathrm{~cm}^{-1}\right): 3084,3022(\mathrm{C}-\mathrm{H}), 2244(\mathrm{CN}), 1588(\mathrm{C}=$ C), 1401, $1314(\mathrm{C}-\mathrm{N}), 1243(\mathrm{C}-\mathrm{O}-\mathrm{C})$.

${ }^{1} \mathrm{H}$ NMR (DMSO- $\left.\mathrm{d}_{6}, \delta, \mathrm{ppm}\right): 8.70(\mathrm{dd}, 2 \mathrm{H}), 8.05(\mathrm{~m}, 4 \mathrm{H}), 7.80$ (d, 2H), 7.45 (dd, 2H), $7.35(\mathrm{dd}, 2 \mathrm{H}), 7.25(\mathrm{~m}, 4 \mathrm{H}), 7.10(\mathrm{~d}, 4 \mathrm{H})$.

${ }^{13} \mathrm{C}$ NMR (DMSO-d $\left.\mathrm{d}_{6}, \delta, \mathrm{ppm}\right): 162.4$ (C6), 158.6 (C16), 155.0 (C7), 152.1 (C15), 147.0 (C10), 142.6 (C13), 138.2 (C5), 136.0 (C12), 131.6 (C9), 125.9 (C4), 124.8 (C8), 124.1 (C3), 122.3 (C14), 118.7 (C2), 117.8 (C18), 117.3 (C17), 110.2 (C1), 61.5 (C11).

Elemental analysis calculated: C, 76.48\%; H, 3.31\%; N, $13.90 \%$. Found: C, $76.76 \%$, H. $3.24 \%$, N, $14.10 \%$. 
2.3.2 9,9-Di[4-(3,4-dicarboxyphenoxy)phenyl]-4,5-diaza fluorene (b). The tetracyano compound a $(1.35 \mathrm{~g}, 2.23 \mathrm{mmol})$ was added to a mixture of potassium hydroxide (12.36 $\mathrm{g}, 89.2 \mathrm{mmol})$ in $100 \mathrm{~mL}$ of a water-ethanol solution ( $1: 1 \mathrm{vol} / \mathrm{vol})$. The suspended liquid was reacted at $80{ }^{\circ} \mathrm{C}$ for 50 hours with stirring till the ammonia was released. After the solution was filtered, the $\mathrm{pH}$ of the solution was adjusted to 2-3 with $20 \%$ dilute hydrochloric acid. The white solid was filtered and washed with distilled water. The product was recrystallized from glacial acetic acid/water 1 : 1 $\mathrm{vol} / \mathrm{vol})$ to give a white solid yield of $1.21 \mathrm{~g}(80 \%)$.

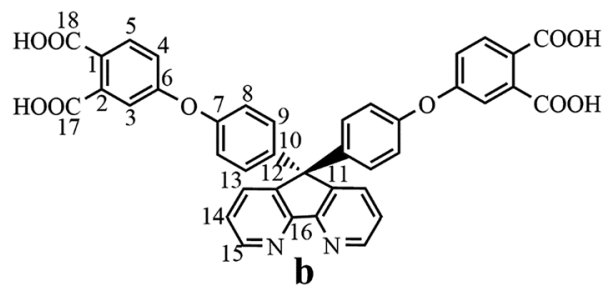

FT-IR (KBr, v, cm $\left.\mathrm{cm}^{-1}\right): 3549(\mathrm{OH}), 1686(\mathrm{C}=\mathrm{O}), 1617,1590$, $1501(\mathrm{C}=\mathrm{C}), 1402(\mathrm{C}-\mathrm{N}), 1228(\mathrm{C}-\mathrm{O}-\mathrm{C})$.

${ }^{1} \mathrm{H}$ NMR (DMSO- $\left.\mathrm{d}_{6}, \delta, \mathrm{ppm}\right): 8.82(\mathrm{dd}, 2 \mathrm{H}), 8.16(\mathrm{dd}, 2 \mathrm{H}), 7.82$ (d, 2H), 7.56 (dd, 2H), 7.33 (d, 4H), 7.17 (dd, 8H).

${ }^{13} \mathrm{C}$ NMR (DMSO-d $\left.{ }_{6}, \delta, \mathrm{ppm}\right): 156.3$ (C18), 155.5 (C17), 148.4 (C6), 146.8 (C16), 145.1 (C7), 141.6 (C15), 137.8 (C10), 133.2 (C13), 130.7 (C12), 128.9 (C2), 126.7 (C9), 125.1 (C1), 122.4 (C4), 120.8 (C8), 117.2 (C14), 116.8 (C3), 115.2 (C5), 69.4 (C11).

Elemental analysis: calculated: $\mathrm{C}, 68.82 \% ; \mathrm{H}, 3.53 \%$; $4.12 \%$. Found: C, $67.28 \%$; H, 3.55\%; N, 4.12\%.

2.3.3 9,9-Di[4-(3,4-dicarboxyphenoxy)phenyl]-4,5-diazafluorene dianhydride (c). The compound $\mathbf{b}(1 \mathrm{~g}, 1.47 \mathrm{mmol})$ was added to $7 \mathrm{~mL}$ of acetic anhydride. The solution was refluxed under the atmosphere of nitrogen for 24 hours. The solution was filtered. Then $14 \mathrm{~mL}$ of glacial acetic acid was added to the filtrate. After cooling down, the precipitate was obtained by filtration and dried under vacuum at $150{ }^{\circ} \mathrm{C}$ to give a yellow solid yield of $0.47 \mathrm{~g}(49.6 \%)$.

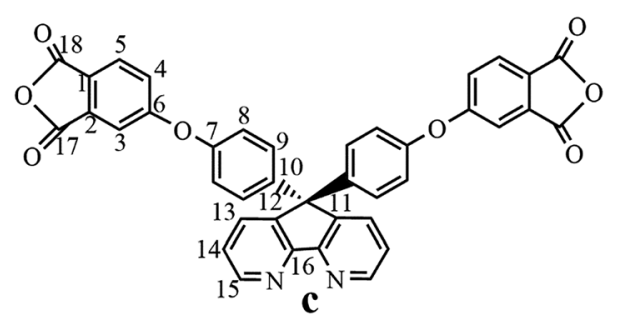

FT-IR (KBr, $\left.v, \mathrm{~cm}^{-1}\right):$ 1785, $1857(\mathrm{C}=\mathrm{O}), 1625,1588,1501$ $(\mathrm{C}=\mathrm{C}), 1410(\mathrm{C}-\mathrm{N}), 1273(\mathrm{C}-\mathrm{O}-\mathrm{C})$.

${ }^{1} \mathrm{H}$ NMR (DMSO-d $\left.{ }_{6}, \delta, \mathrm{ppm}\right): 8.72(\mathrm{dd}, 2 \mathrm{H}), 8.08(\mathrm{dd}, 2 \mathrm{H}), 8.02$ (dd, 2H), 7.45 (d, 6H), 7.30 (d, 2H), 7.10 (dd, 4H).

${ }^{13} \mathrm{C}$ NMR (DMSO-d $\left.{ }_{6}, \delta, \mathrm{ppm}\right): 165.5$ (C18), 164.5 (C17), 164.3 (C6), 158.7 (C16), 155.5 (C7), 152.2 (C15), 147.1 (C10), 142.6 (C13), 136.1 (C12), 132.8 (C2), 129.8 (C9), 127.0 (C1), 126.6 (C4), 126.0 (C3), 122.4 (C8), 114.9 (C5), 114.8 (C14), 61.9 (C11).

Elemental analysis: calculated: $\mathrm{C}, 72.67 \% ; \mathrm{H}, 3.11 \%$, , $4.34 \%$. Found: C, $70.34 \%$; H, 3.22\%; N, 4.08\%.

Melting point: $208-210{ }^{\circ} \mathrm{C}$.
2.3.4 Synthesis of polyimides. A typical one-step method for the synthesis of polyimides was as follows. A mixture of $1 \mathrm{~mol}$ of diamine, $1 \mathrm{~mol}$ of dianhydride monomer c and $\mathrm{N}$ methylpyrrolidone was reacted at room temperature for 24 hours. Then $2 \mathrm{~mL}$ of toluene was added to the homogeneous solution and the mixture was reacted at $180^{\circ} \mathrm{C}$ for 4 hours. The viscous solution was poured into methanol to obtain the fibrous polyimide. The mixture was filtered to give the polyimide solid. The resulting polyimide solid was dried at $80{ }^{\circ} \mathrm{C}$.

2.3.5 Preparation of polyimide films. $1 \mathrm{~g}$ of the resulting polyimide was dissolved in $20.2 \mathrm{~mL}$ of DMF at $80^{\circ} \mathrm{C}$. A $0.45 \mathrm{~mm}$ filter syringe was used to filter the PI solution. Then, the filtrate was uniformly coated onto a clean and dry glass, and dried at $90{ }^{\circ} \mathrm{C}$ for $6 \mathrm{~h}$ to obtain a flexible and transparency PI film.

\section{Results and discussions}

\subsection{Synthesis and characterization of dianhydride monomers}

The synthesis of the dianhydride monomer included three stages as shown in Scheme 1. In the first stage, the bis(ether dinitrile) was obtained via a nucleophilic substitution reaction between 9,9-di-(4-hydroxyphenyl)-4,5-diazafluorene and 4-fluorophthalonitrile. The second stage consisted of an alkaline hydrolysis reaction. The bis(ether dinitrile) was hydrolyzed into bis(ether diacid) in ethanolic potassium hydroxide solution. In the third stage, the bis(ether diacid) was subjected to a dehydration reaction in acetic anhydride to obtain the bis(ether andydride). Structures of the precursors and dianhydride monomer were determined by elemental analysis, ${ }^{1} \mathrm{H} \mathrm{NMR},{ }^{13} \mathrm{C}$ NMR and FT-IR spectra.

The FT-IR spectra of compounds $\mathbf{a}, \mathbf{b}$ and $\mathbf{c}$ are compared in Fig. 1. The sharp cyanide peak near $2234 \mathrm{~cm}^{-1}$ corresponded to the bis(ether dinitrile) (Fig. 1a). Hydrolysis of the bis(ether dinitrile) caused both the disappearance of the cyanide peak and the appearance of a broad hydroxyl peak, which was observed from $3423 \mathrm{~cm}^{-1}$ to $2614 \mathrm{~cm}^{-1}$. Additionally, the sharp carbonyl absorption peak was observed near $1700 \mathrm{~cm}^{-1}$. After the chemical cyclization of the bis(ether diacid), a sharp absorption peak near $1700 \mathrm{~cm}^{-1}$ disappeared and the absorption peaks for the carbonyl groups of the five-membered ring appear at $1850 \mathrm{~cm}^{-1}$ and $1775 \mathrm{~cm}^{-1}$. There is also an absorption peak near $1270 \mathrm{~cm}^{-1}$, correlating to the ether bond, and the small absorption peak near $1401 \mathrm{~cm}^{-1}$ corresponding to the absorption peak of a typical $\mathrm{C}-\mathrm{N}$ stretching bond. In the ${ }^{1} \mathrm{H}$ NMR spectra of compound a (Fig. 2), the aromatic ring hydrogen atoms of bis(ether dinitrile) were observed between $8.70 \mathrm{ppm}$ and $7.10 \mathrm{ppm}$, and the hydrogen atom for the hydroxyl group was absent. This gives the evidence that the hydroxy groups of 9,9-di(4-hydroxyphenyl)-4,5-diazafluorene had been reacted completely. The ${ }^{13} \mathrm{C}$ NMR spectra of compound a revealed a single peak at $61.5 \mathrm{ppm}$, indicating that the presence of the spirofluorene structure and a total of 18 carbon atoms, which was consistent with the structure of target compound a. Fig. 3 and 4 displayed the ${ }^{1} \mathrm{H}$ and ${ }^{13} \mathrm{C}$ NMR spectra of compound $\mathbf{b}$ (bis(ether diacid)) and compound $\mathbf{c}$ (bis(ether andydride)), respectively. Based on the integration of aromatic 


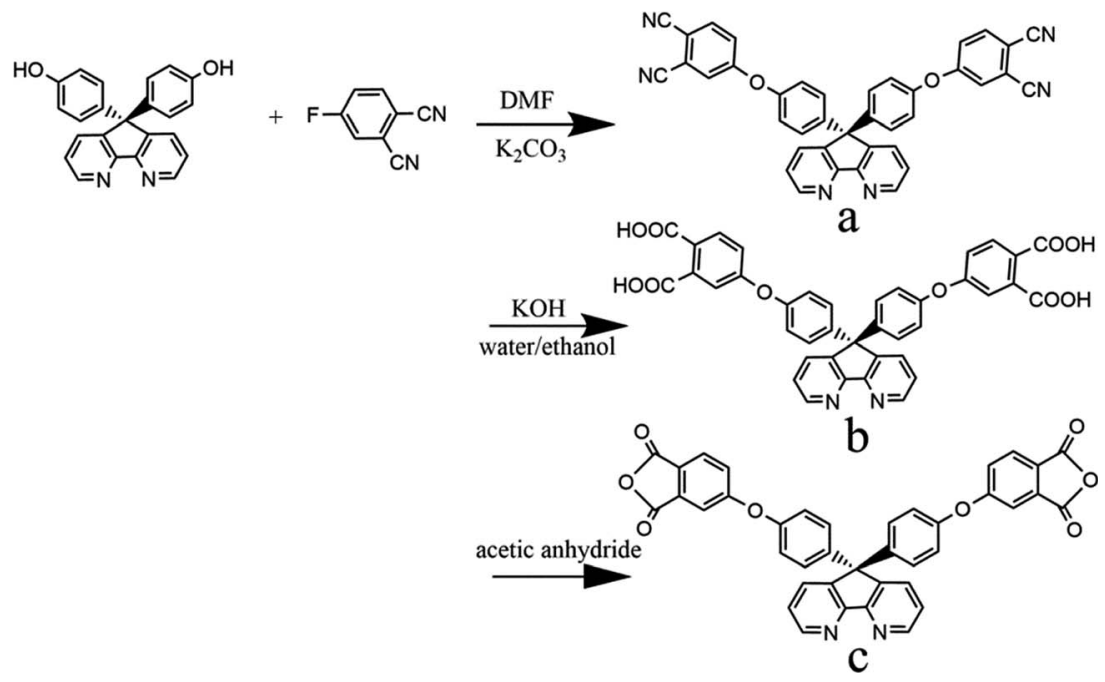

Scheme 1 Synthesis of dianhydride monomer c.

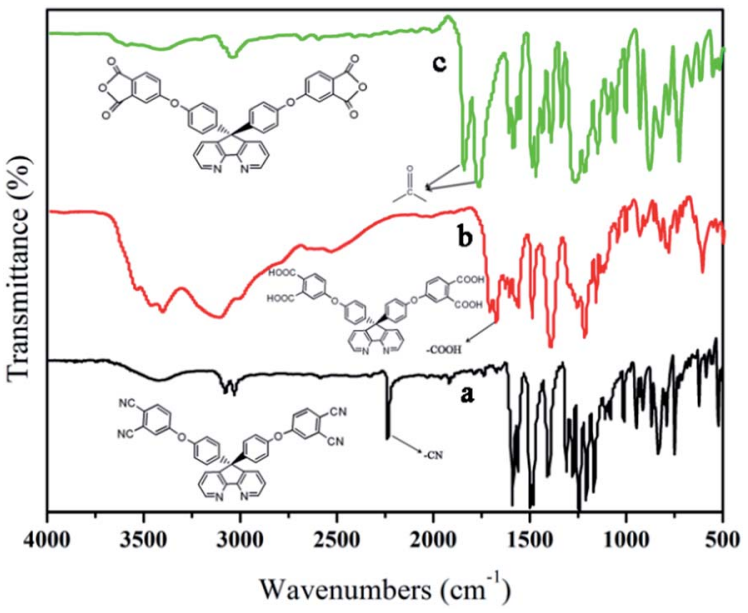

Fig. 1 FT-IR spectra of cyano compound a, carboxyl compound $b$ and dianhydride compound $\mathrm{c}$.

region in the ${ }^{1} \mathrm{H}$ NMR spectra and shift of the carbonyl carbon signal to a lower field in the ${ }^{13} \mathrm{C}$ NMR spectra, it could be determined that the carboxyl group had been successfully cyclodehydrated. Based on the FT-IR and NMR data consisting with all compounds structure was assigned in experimental part and Fig. 1-4, the dianhydride monomer was successfully synthesized.

\subsection{Synthesis and characterization of PIs}

In this paper, the polyimides in Scheme 2 were synthesized via one-step method. The obtained novel dianhydride monomer $\mathbf{c}$ was polymerized with four different diamines 1-4, respectively. As shown in Table 1, number-average molecular weights $\left(M_{\mathrm{n}}\right)$ and the weight-average molecular weights $\left(M_{\mathrm{w}}\right)$ were located in the ranges of $22600-45700$ and $35800-88300$. The structures of the polyimides were characterized by FT-IR and ${ }^{1} \mathrm{H}$ NMR. The FT-IR spectra of PI-1, PI-2, PI-3 and PI-4 were combined in Fig. 5.
All the polyimides showed characteristic imide absorption peaks near $1778 \mathrm{~cm}^{-1}$ and $1720 \mathrm{~cm}^{-1}$ corresponding to the imide ring of the polyimide. No peak appearing around $1650 \mathrm{~cm}^{-1}$ indicated that PAA was completely converted to polyimide during the high temperature dehydration period. The absorption peak near $1350 \mathrm{~cm}^{-1}$ was assigned to the $\mathrm{C}-\mathrm{N}$ bond stretching vibration, while the strong peaks appearing at $1100 \mathrm{~cm}^{-1}$ and $1300 \mathrm{~cm}^{-1}$ is assigned to the ether bond vibration peaks. The typical ${ }^{1} \mathrm{H}$ NMR spectrum of PI-3 is shown in Fig. 6. All of the proton resonances were - between $7.0 \mathrm{ppm}$ and $8.7 \mathrm{ppm}$. Due to the strong electron withdrawing and resonance of pyridine groups, the protons assigned to $\mathrm{H} 12$ close to the pyridine ring appeared at the lowest field at $8.7 \mathrm{ppm}$. Aromatic ether had the electron-donating property, which leaded to the shift of protons $\mathrm{H} 8$ and $\mathrm{H} 9$ to a higher field. The assignment results of FT-IR and ${ }^{1} \mathrm{H}$ NMR spectra indicated that the target polyimides were successfully synthesized. The solutions of the polyimides were casted onto a clean and dry glass, and dried at $90{ }^{\circ} \mathrm{C}$ for $6 \mathrm{~h}$ to obtain flexible films with good optical transparency as shown in Fig. 7. The thickness data of polyimide films for PI-1, PI-2, PI-3 and PI-4 were $53 \mu \mathrm{m}, 38 \mu \mathrm{m}, 42 \mu \mathrm{m}$ and $39 \mu \mathrm{m}$, respectively.

\subsection{Thermal properties of the PIs}

The thermal properties of the PIs were measured using DMA and TGA. The thermal stability of the polyimides was measured using TGA (Fig. 8). Notably, the $T_{10 \%}$ of PI-1 was observed at $552^{\circ} \mathrm{C}$ under nitrogen atmosphere. The heat loss temperatures of other polyimides were lower than PI-1, which could relate to the diamine structure. The incorporation of large pendant groups increased the distance between molecules and reduced the bulk density between molecules, thereby leading to a reduction of polyimide rigidity. ${ }^{17,38,39}$ Another reason for the low heat loss temperature was due to the introduction of a large number of flexible ether bonds. The char yield at $800{ }^{\circ} \mathrm{C}$ under nitrogen atmosphere between $45 \%$ and $65 \%$. The TGA data 

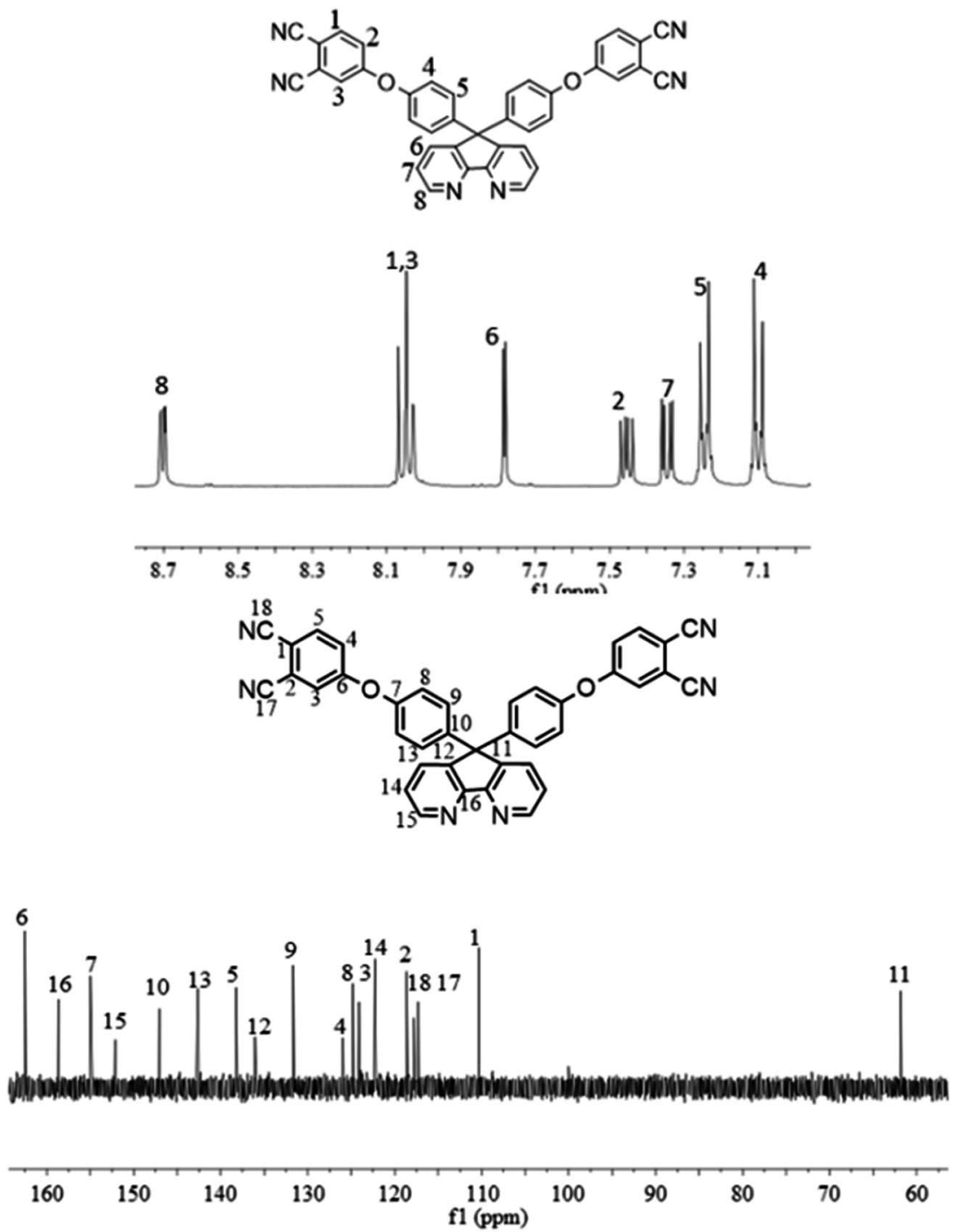

Fig. $2{ }^{1} \mathrm{H}$ and ${ }^{13} \mathrm{C}$ NMR spectra of compound $\mathrm{a}$ in DMSO- $\mathrm{d}_{6}$.

indicated that the resulting polyimide exhibited good thermal stability, while simultaneously retaining high solubility and good light transmission (Fig. 7).

The $T_{\mathrm{g}}$ of all polyimides were obtained from DMA as shown in Fig. 9 and Table 2. Usually, the $T_{\mathrm{g}}$ value is closely related to the molecular bulk density and the composition of the polymer chains. All PIs exhibited high $T_{\mathrm{g}}$ values between $270{ }^{\circ} \mathrm{C}$ and $31{ }^{\circ} \mathrm{C}$, which suggested that the introduction of the 4,5-diazafluorene structure can increase the glass transition temperature of the polyimide. The high $T_{\mathrm{g}}$ of the polyimides was due to the high content of aromatic units, and the effect of the $\mathrm{sp}^{3}$ hybridized carbon on the 4,5-diazafluorene group. ${ }^{30}$ In this study, because the dianhydride were polymerized with different diamines, the differences of obtained PIs' $T_{\mathrm{g}}$ related to the diamine structures used in PIs synthesis. Because of the presence of two visible ether bond units and trifluoromethyl $\left(\mathrm{CF}_{3}\right)$ structures, which would produce a plasticizing effect due to its geometrical and free volume, ${ }^{9}$ the PI- 3 exhibited the lowest glass transition temperature of $270{ }^{\circ} \mathrm{C}$. On the other hand, the $T_{\mathrm{g}}$ values also depended upon the polarity and rigidity of diazafluorene units. For example, the polymers containing bipyridine structures had higher $T_{\mathrm{g}}$ values compared to polymers containing biphenyl structures $\left(274^{\circ} \mathrm{C} v s .241{ }^{\circ} \mathrm{C}\right) .{ }^{26}$

\subsection{The solubility of PIs and film property}

The solubility of the resulting PIs was tested in organic solvents as shown in Table 3 . The results indicated that the resulting polyimides were soluble in commonly used organic solvents such as NMP, DMAc, DMF and $m$-cresol. Notably, PI-3 and PI-4 could be dissolved in dichloromethane, tetrahydrofuran and 1,4-dioxane. Compared with the traditional aromatic polyimides, the obtained polyimides exhibited better solubility in general. ${ }^{36}$ The better solubility was explained by the presence of both the diazafluorene moiety and numerous ether bonds in the polymer chain. The diazafluorene moiety increased the distance between the polymer molecules, thereby reducing the aggregation of the chain and leading to better solvent dispersion. The 

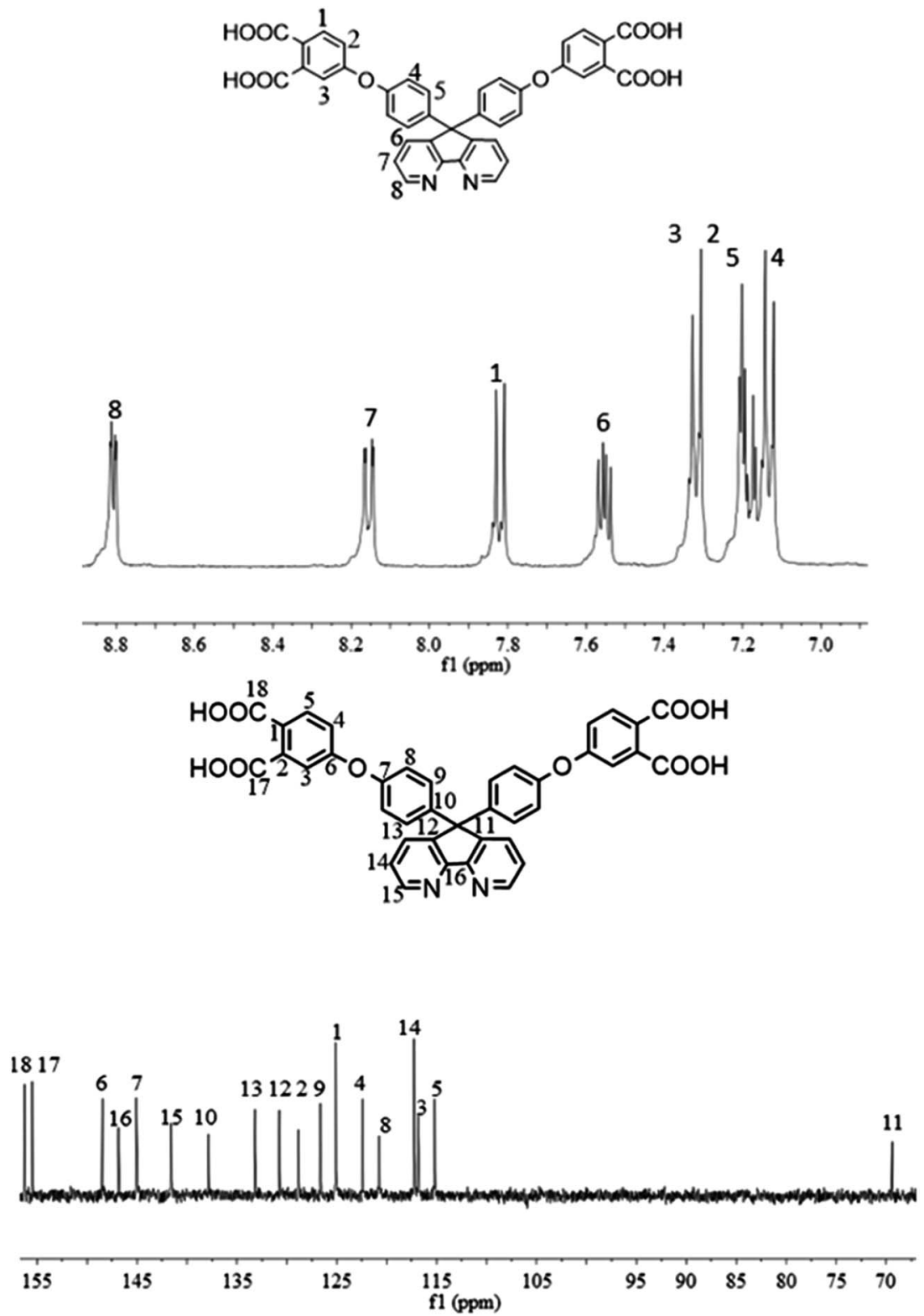

Fig. $3{ }^{1} \mathrm{H}$ and ${ }^{13} \mathrm{C}$ NMR spectra of compound $b$ in DMSO- $d_{6}$.

introduction of flexible ether bond groups changed the polymer chain twist angle, allowed the aromatic ring to rotate freely, therefore, the solubility of polyimides were improved effectively. ${ }^{38}$ Moreover, the presence of the pyridine rings in the diazafluorene moiety also increased the polymer solubility, because the protonation of the lone pair electrons on the nitrogen atom can increase the solubility of the resulting polyimide in polar solvents, and pyridine rings could provide strong intermolecular interactions. ${ }^{34}$ Because of the incorporation of trifluoromethyl groups, both PI-3 and PI-4 were soluble in tetrahydrofuran, dichloromethane and 1,4-dioxane. ${ }^{34,38}$

The storage modulus of the resulting PIs was tested using DMA as shown in Fig. 10. In general, the resulting polyimides had good storage modulus in the range of 490-813 MPa. PI-1 had the highest storage modulus, which was attributed to a higher diazafluorene content of a polymer structure unit than that of PI-2, PI-3 and PI-4. This showed that the diazafluorene unit could improve the storage modulus of the resulting polyimides. ${ }^{38,39}$ Because the bulky trifluoromethyl groups could efficiently reduce the structural regularity of the polyimide chain and improve the polarity correspondingly, ${ }^{39}$ the storage modulus of the PI-2 is higher than PI- 3 and PI-4 as shown in Fig. 10. The tensile strength and break elongation results of the polyimides are shown in Fig. 11 and Table 1. The films exhibited excellent tensile strength between $92 \mathrm{MPa}$ and $105 \mathrm{MPa}$ and break elongation from $4.99 \%$ to $24.8 \%$. The presence of bipyridine enhanced the tensile strength of polyimides in comparison with other traditional polyimides and fluorene containing polyimides. $^{26,36}$ The results of tensile strength in Fig. 11 demonstrated that PI-1 had higher tensile strength and break 

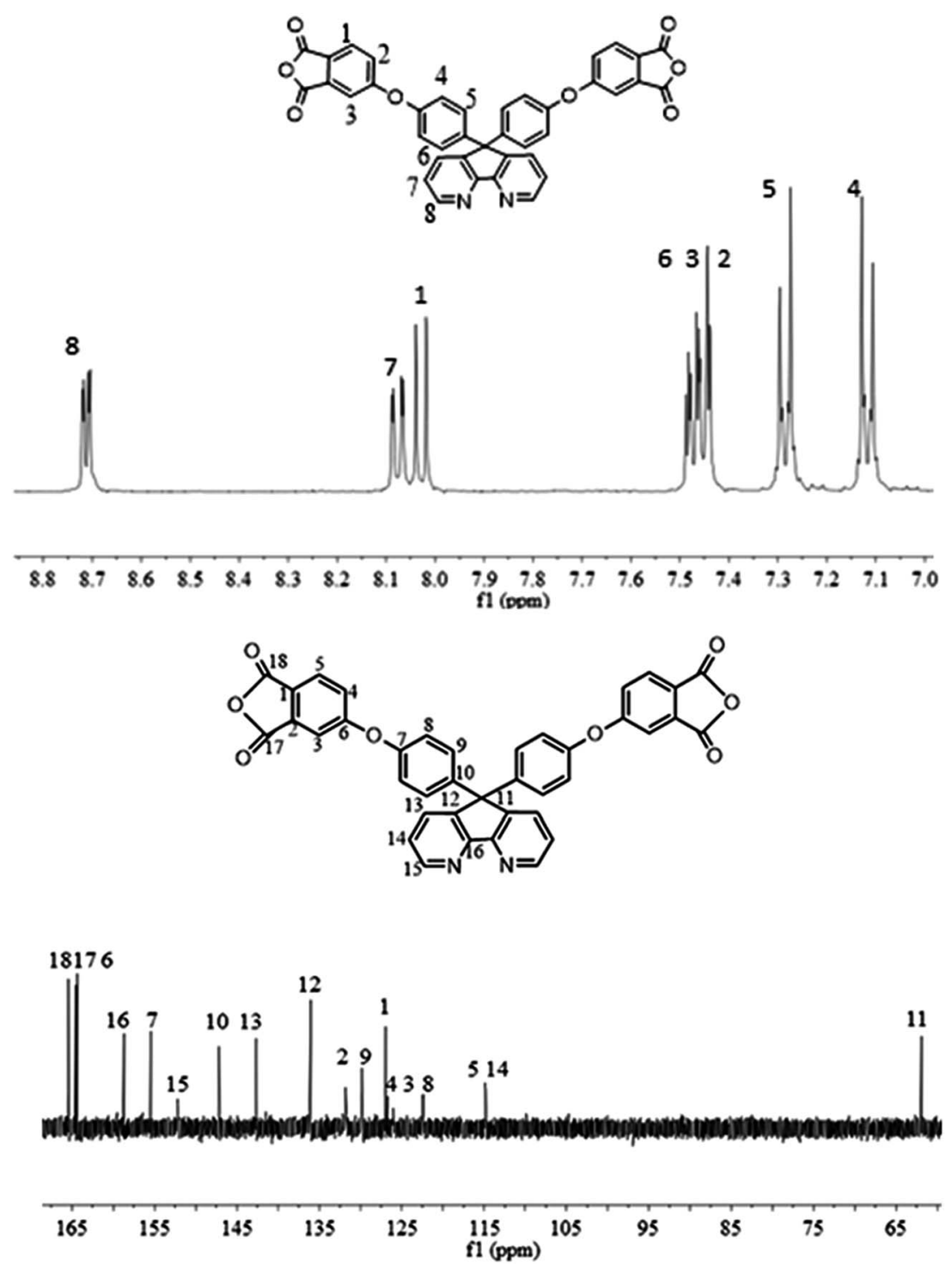

Fig. $4{ }^{1} \mathrm{H}$ and ${ }^{13} \mathrm{C}$ NMR spectra of compound $\mathrm{c}$ in DMSO- $\mathrm{d}_{6}$.

elongation than PI-2, PI-3 and PI-4, which also could be explained by the higher diazafluorene content of PI-1 contributing the mechanical properties of polyimide. ${ }^{38}$ Moreover, the introduction of polar pyridine ring in diamine monomer leaded to the higher tensile strength of PI-3 in comparison with that of PI-4, which also indicated that the pyridine groups could improve the enhancement of mechanical strength effectively. ${ }^{34}$

\subsection{Optical transparency and X-ray diffraction}

All the obtained polyimide films exhibited good quality and flexible light-colored. The UV-visible spectroscopy (Fig. 12) was used to measure the optical transparency of films. In Table 4 lists the cut-off wavelength of the polyimide films (absorption edge, $\left.\lambda_{0}\right)$.

The UV-visible spectra of polyimide films with thicknesses of approximately $20 \mu \mathrm{m}$ as shown in Fig. 12 demonstrated that the transparency of each resulting polyimide film is over $71 \%$.
Moreover, the films of PI-1 and PI-2 exhibited excellent transparency of $80 \%$. Optical transparency of all the resulting polyimide films was over $60 \%$ at $550 \mathrm{~nm}$, however, the Kapton film showed transparency of $54 \%$ at $550 \mathrm{~nm} .{ }^{9}$ The results demonstrated that these 4,5-diazafluorene-containing polyimides have higher transparency compared with that of Kapton. ${ }^{38}$ Because of strong inter-molecular interactions and charge transfer complex (CTC) of aromatic polyimides, aromatic polyimides exhibited strong absorption between the UV and visible area. However, the introduction of 4,5-diazofluorene acid anhydride increased the steric hindrance, thereby reducing the formation of transfer complexes and disrupting the structural integrity of the chain. Consequently, the introduction of 4,5-diazofluorene unit improved the transparency of the polyimide. ${ }^{39}$ Interestingly, PI-3 and PI-4 containing $\mathrm{CF}_{3}$ should have better optical transparency than that of PI-1 and PI-2, but in this work, PI-2 exhibited the best optical transparency (Fig. 12). We speculate the results may be attributed to the following three factors: (i) 


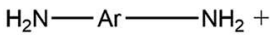<smiles>O=C1OC(=O)c2cc(Oc3ccc(C(c4ccc(Oc5ccc6c(c5)C(=O)OC6=O)cc4)(c4ccccn4)c4ccccn4)cc3)ccc21</smiles>

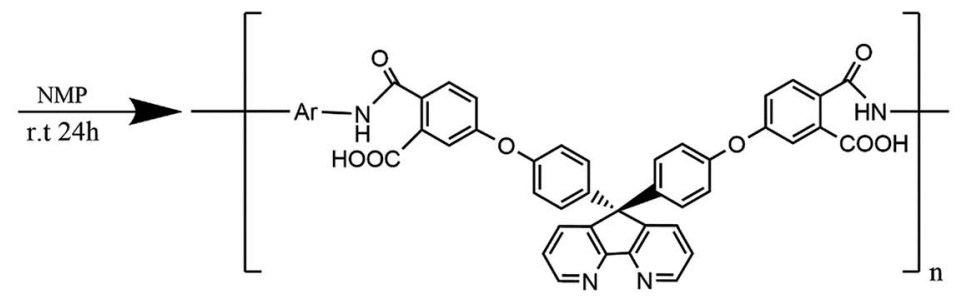

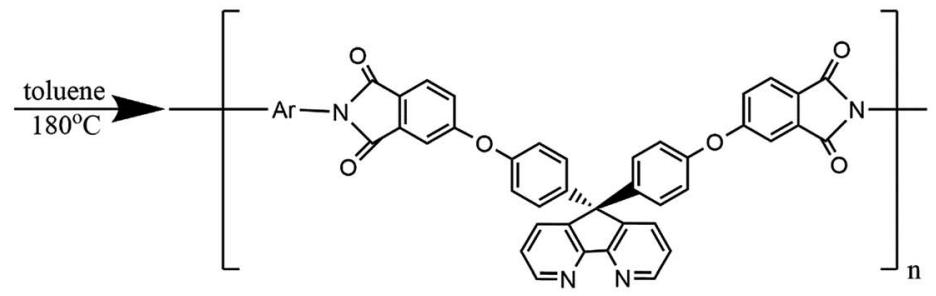

$\mathrm{Ar}=$
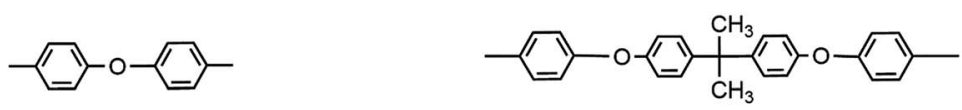

1

2
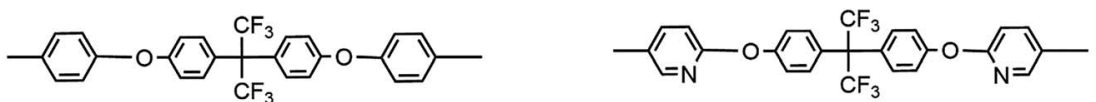

3

4

Scheme 2 Synthesis of the polyimides.

Table 1 GPC datas and thin film tensile properties of the polyimides

\begin{tabular}{|c|c|c|c|c|c|}
\hline \multirow[b]{2}{*}{ Polyimide } & \multicolumn{3}{|c|}{ GPC datas of polyimide } & \multicolumn{2}{|c|}{$\begin{array}{l}\text { Tensile properties of the } \\
\text { polyimide films }\end{array}$} \\
\hline & $M_{\mathrm{n}}$ & $M_{\mathrm{w}}$ & $M_{\mathrm{w}} / M_{\mathrm{n}}$ & $\begin{array}{l}\text { Tensile } \\
\text { strength (MPa) }\end{array}$ & $\begin{array}{l}\text { Elongation at } \\
\text { break }(\%)\end{array}$ \\
\hline PI-1 & 32200 & 47600 & 1.48 & $105 \pm 5.1^{a}$ & 24.8 \\
\hline PI-2 & 22600 & 35800 & 1.58 & $92 \pm 2.0$ & 5.75 \\
\hline PI-3 & 45700 & 88300 & 1.93 & $93 \pm 1.8$ & 5.49 \\
\hline PI-4 & 28000 & 45000 & 1.61 & $100 \pm 1.8$ & 4.99 \\
\hline
\end{tabular}

the 4,5-diazafluorene plays a leading role in the transparency properties. Generally, the rigid structure, strong inter-molecular interactions and charge transfer complex (CTC) of aromatic polyimides always lead to dark brownish colour, and the introduction of $\mathrm{CF}_{3}$ could reduce the CTC formation because of

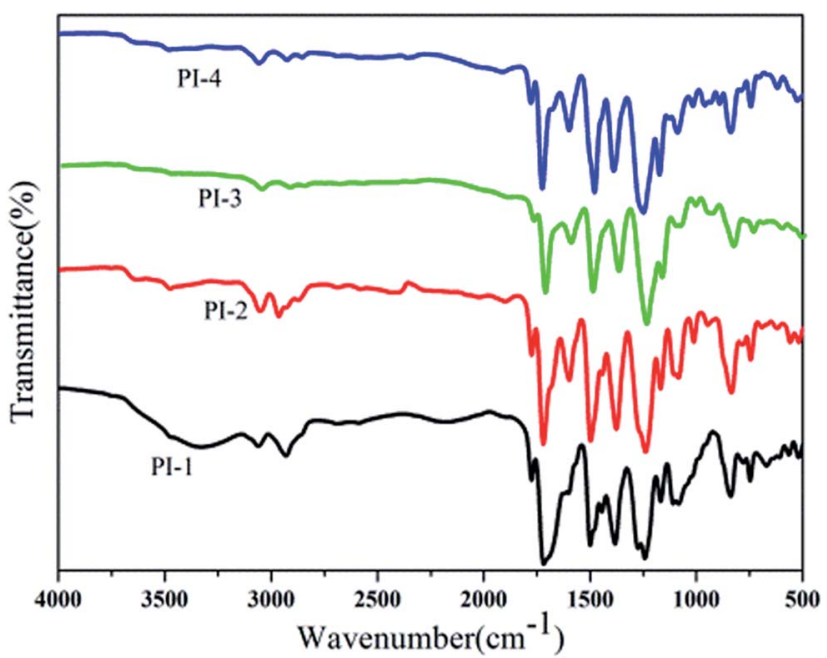

Fig. 5 FT-IR spectra of polyimides. 


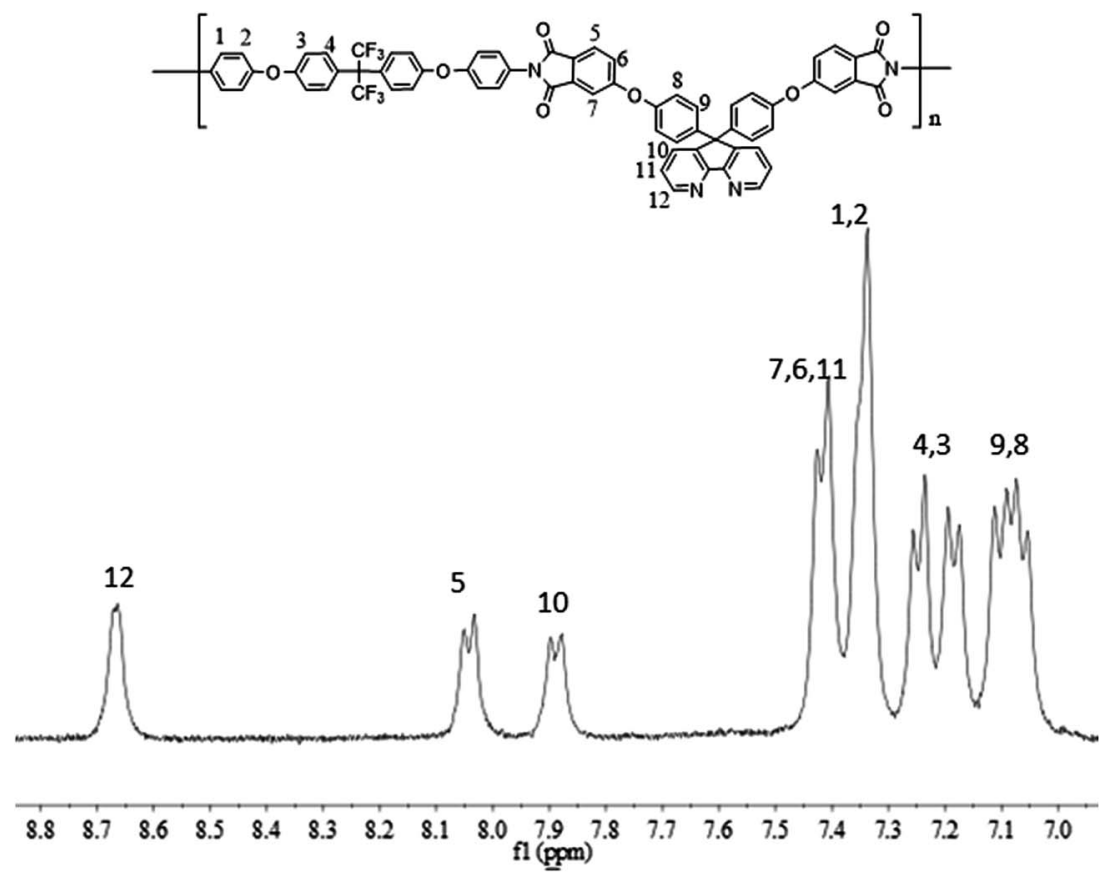

Fig. $6{ }^{1} \mathrm{H}$ NMR spectrum of PI-3.

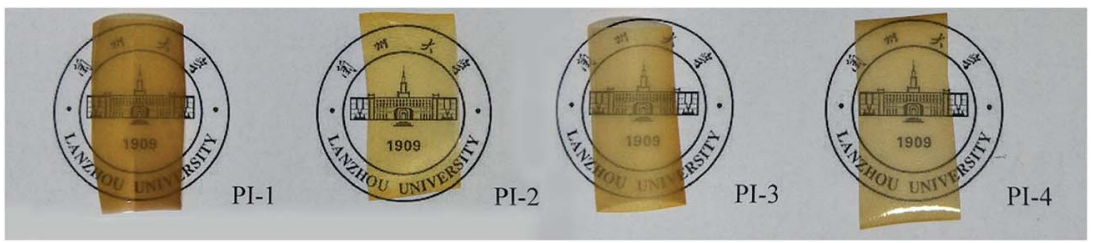

Fig. 7 Photographs of PI-1, PI-2, PI-3, and PI-4.

the strong electron-withdrawing effect. ${ }^{42}$ However, in this work, the electronegativity of $\mathrm{CF}_{3}$ may consist the inter-molecular CTC formation with pyridine ring. The better optical transparency of PI-3 in comparison with PI-4, and the better optical transparency of PI-1 and PI-2 without $\mathrm{CF}_{3}$ in comparison with PI-3

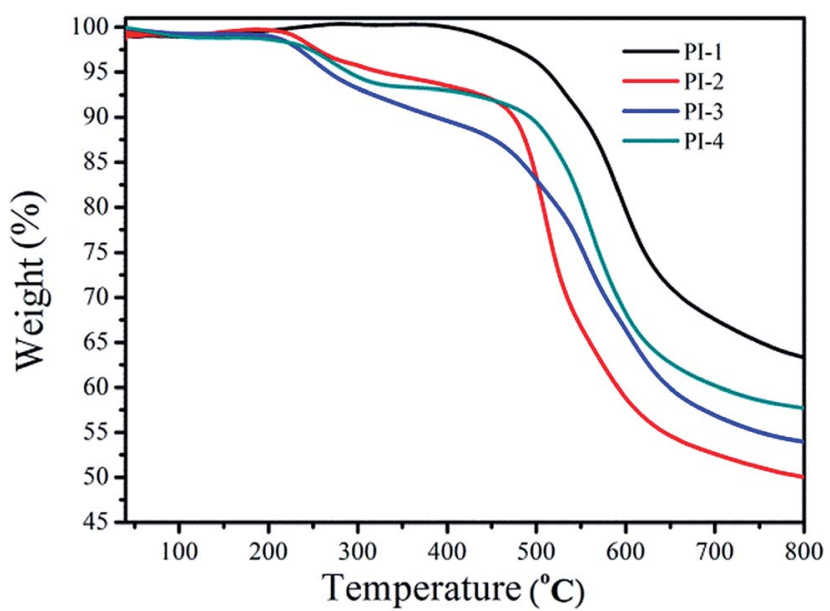

Fig. 8 TGA curves of polyimides at a heating rate of $20^{\circ} \mathrm{C} \mathrm{min}^{-1}$. and PI-4 containing $\mathrm{CF}_{3}$, also give the evidence that the simultaneous introduction of pyridine and $\mathrm{CF}_{3}$ would reduce optical transparency of PIs. (ii) Bikson et al. claimed that the dianhydride structure is more influential than diamine structure in

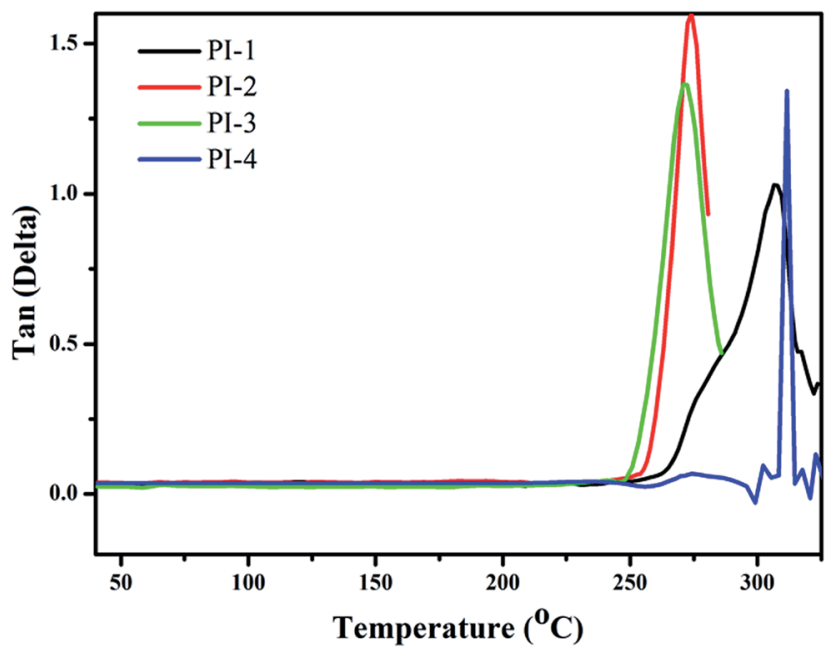

Fig. 9 Dynamic mechanical spectra for the polyimides at $1 \mathrm{~Hz}$. 
Table 2 Thermal properties of the PEls and reference polymer

\begin{tabular}{lllll}
\hline Polyimide & $T_{5 \%}{ }^{a}\left({ }^{\circ} \mathrm{C}\right)$ & $T_{10 \%}\left({ }^{\circ} \mathrm{C}\right)$ & $T_{\mathrm{g}}{ }^{b}\left({ }^{\circ} \mathrm{C}\right)$ & $R_{800}{ }^{c}(\%)$ \\
\hline PI-1 & 513 & 552 & 306 & 63 \\
PI-2 & 326 & 474 & 274 & 50 \\
PI-3 & 267 & 387 & 270 & 53 \\
PI-4 & 289 & 493 & 311 & 57 \\
Ref-PI $^{d}$ & - & 542 & 241 & 62.5
\end{tabular}

${ }^{a}$ Thermal decomposition temperature for $5 \%$ weight loss. ${ }^{b}$ Glass transition temperature was measured by DMA. ${ }^{c}$ Residual weight at $800{ }^{\circ} \mathrm{C} .{ }^{d}$ The PI chemical structure is synthesized with 9,9-bis[4(3,4-dicarboxyphenoxy)phenyl]fluorene dianhydride and bis[4(aminophenoxy)4-phenyl]isopropylidene from ref. 26.

Table 3 Solubility $^{a}$ of the polyimides prepared via chemical imidization $^{b}$

\section{Solvent}

$$
m^{-} \quad 1,4-
$$

Polymers NMP DMAc DMF Cresol THF Dioxane Dichloromethane

\begin{tabular}{llllllll}
\hline PI-1 & ++ & ++ & +- & ++ & -- & -- & -- \\
PI-2 & ++ & ++ & ++ & ++ & +- & +- & -- \\
PI-3 & ++ & ++ & ++ & ++ & ++ & ++ & ++ \\
PI-4 & ++ & ++ & ++ & ++ & ++ & ++ & ++
\end{tabular}

${ }^{a}$ Solubility was tested with a $10 \mathrm{mg}$ sample in $1 \mathrm{~mL}$ solvent at $25^{\circ} \mathrm{C}$. ${ }^{b}$ Solubility: ++ , soluble at $25{ }^{\circ} \mathrm{C}$; +- , partial soluble at $25{ }^{\circ} \mathrm{C}$, after heating soluble at $80{ }^{\circ} \mathrm{C} ;--$, insoluble even in heating at $80{ }^{\circ} \mathrm{C}$.

determining the color intensity. ${ }^{43}$ Moreover, in this work, because the trifluoromethyl groups of the diamine units are far from the imide ring, the $\mathrm{CF}_{3}$ electron-withdrawing effect slightly influences the charge transfer of imide groups. ${ }^{\mathbf{4 4}}$ (iii) Because high flexible ether linkages content contributes to the light color of PIs, PI-2 had better optical transparency than PI-1 as expected. ${ }^{\mathbf{4 4}}$

The morphological structure of the polyimides was analyzed by wide-angle X-ray diffraction, $2 \theta$ ranging from 10 to $90^{\circ}$ as

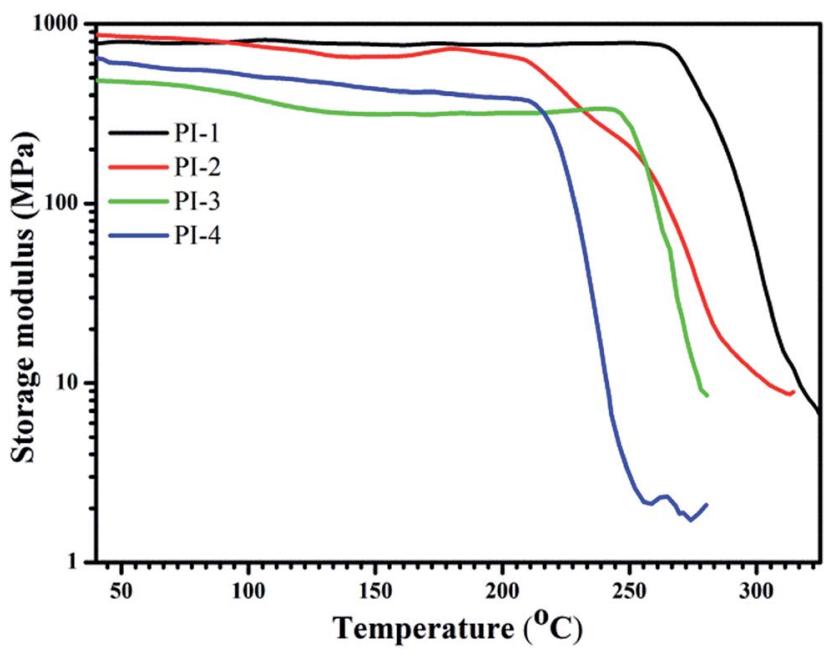

Fig. 10 Storage modulus polyimide films in DMA.

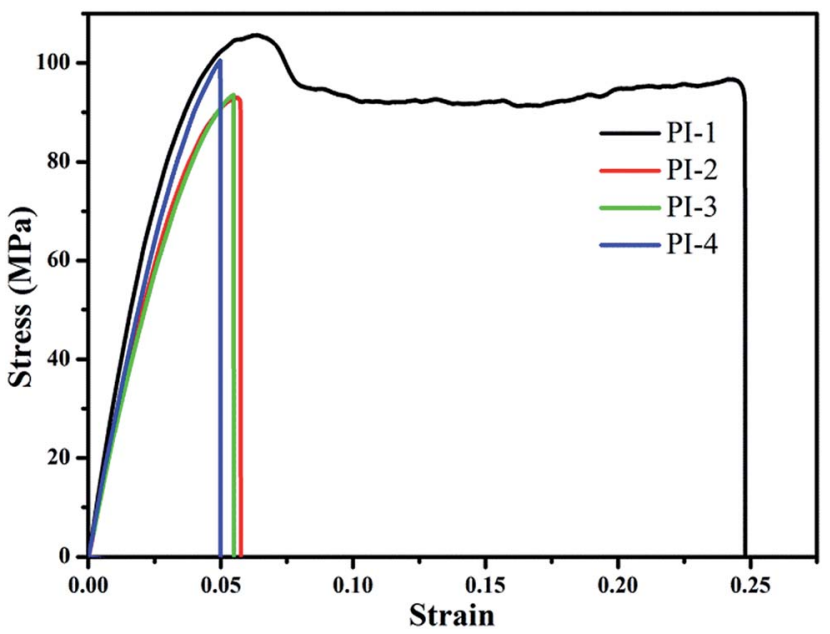

Fig. 11 Stress versus strain curves of Pls.

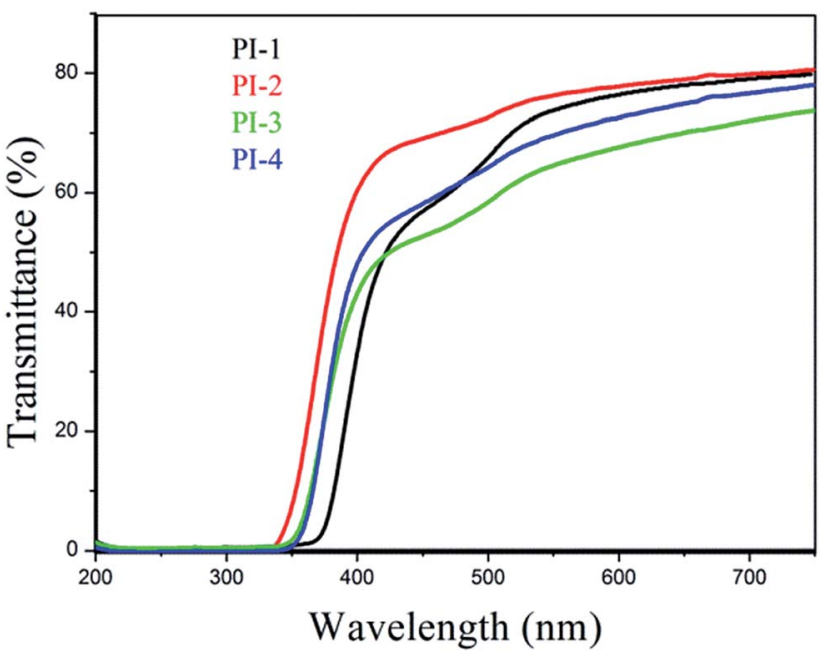

Fig. 12 UV-visible spectra of polyimide films.

shown in Fig. 13. A set of wider diffraction peak was observed for all obtained polyimides, which gave the evidence that the polyimides did not exhibit any crystallinity attributed to the incorporation of the 4,5-diazafluorene structure and flexible ether disrupting the structural regularity of the polyimide chain. $^{34,38}$

\subsection{Dielectric constant and water absorption}

The dielectric constants of all PIs were measured from $100 \mathrm{~Hz}$ to $1 \mathrm{MHz}$ at $20{ }^{\circ} \mathrm{C}$ and $50 \%$ relative humidity (Fig. 14). The dielectric constants are between 2.78 and 3.38, which are lower than that of commercial film such as Kapton film (3.5 at $1 \mathrm{kHz}$ ) due to the nonplanar characteristic of the 4,5-diazofluorene structure. ${ }^{38}$ Moreover, the PI-3 performed the lowest dielectric constant, because the large electronegativity and the low polarizability of the fluorine atom result in permanent dipole moments for the $\mathrm{CF}_{3}$ groups, and the large volume of 4,5diazofluorene structure reduced the bulk density, thereby 
Table 4 Moisture absorption, dielectric constants, refractive index and cutoff wavelength $\left(\lambda_{0}\right)$ from UV-visible spectra of polyimides ${ }^{a}$

\begin{tabular}{|c|c|c|c|c|c|c|}
\hline Polymer & Moisture absorption $^{b}(\%)$ & Dielectric constant & Refractive index & $\lambda_{0}(\mathrm{~nm})$ & $T_{450}(\%)$ & Transparency $^{c}$ \\
\hline PI-1 & $4.8 \%$ & 2.96 & 1.68 & 356 & 56.9 & 79.8 \\
\hline PI-2 & $4.9 \%$ & 3.01 & 1.42 & 337 & 69.3 & 80.9 \\
\hline PI-4 & $2.8 \%$ & 3.38 & 1.55 & 349 & 58.5 & 78.4 \\
\hline
\end{tabular}

${ }^{a} \lambda_{0}$, cutoff wavelength; $T_{450}$, transmittance at $450 \mathrm{~nm} .{ }^{b}$ Moisture absorption of polyimide films was measured by immersing the films in distilled water at room temperature for $24 \mathrm{~h} .{ }^{c}$ Average transmittance in the visible region $(400-780 \mathrm{~nm})$.

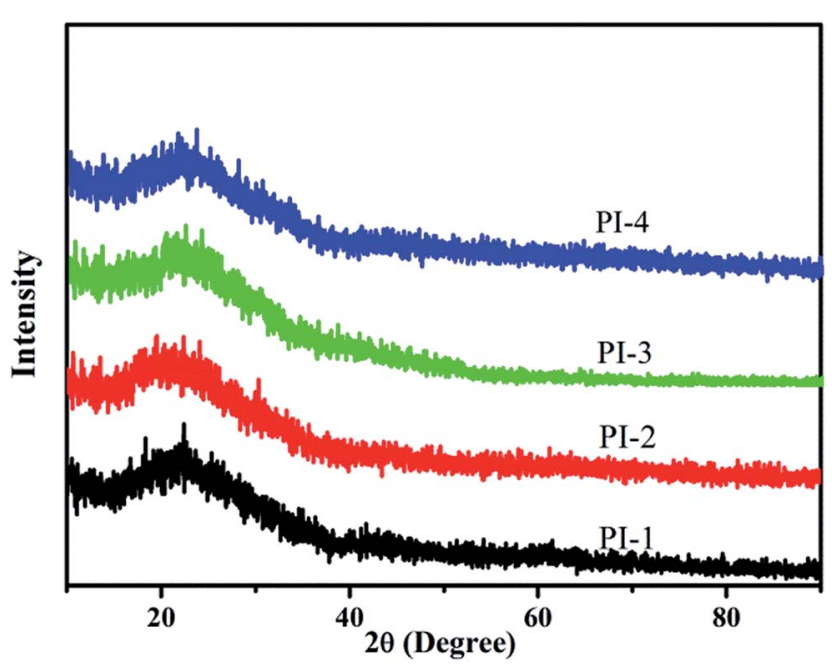

Fig. 13 Wide-angle X-ray diffraction curves of the polyimide films.

increasing the free volume of the polyimide. However, the increase dielectric constant of PI- 4 may be caused by interactions between the diamine pyridine ring and the dianhydride pyridine ring. In addition, the dielectric constants of PI-1, PI-2, and PI-3 were practically unaffected by the frequency changing. However, the dielectric constant of PI-4 had clearly dropping characteristic, which was rationalized by the space charge polarization..$^{10,34,38}$

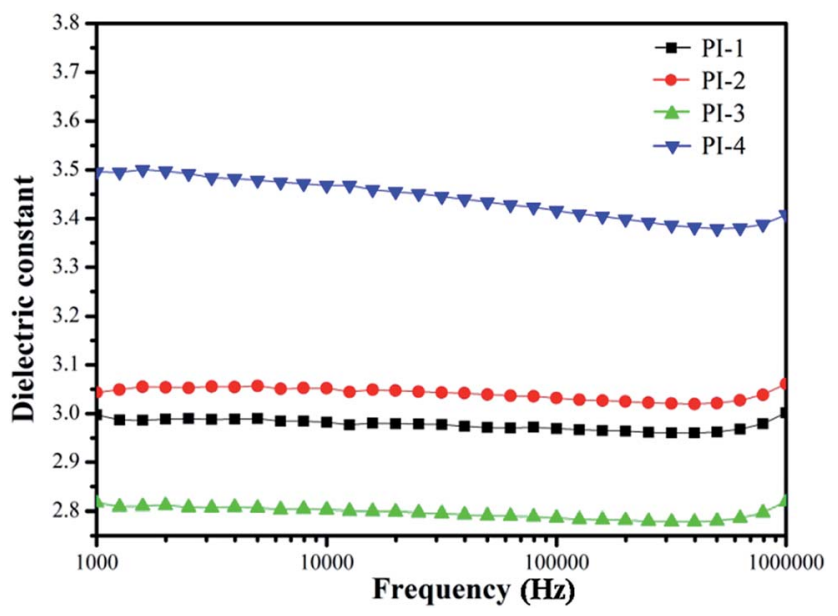

Fig. 14 Dielectric constant of the Pls.
The obtained polyimide films exhibited low water absorption of $2.8-4.9 \%$ (Table 4 ). As expected, all the PI showed low water absorption, due to the proofing effect of 4,5-diazofluorene and trifluoromethyl groups. ${ }^{26}$

A Gaertner L116B spectroscopic ellipsometer was used to measure the refractive index of films, the values of the resulting polyimides located between 1.32 and 1.68 at $650 \mathrm{~nm}$ as shown in Table 4. Because the molar refractive index of the pyridine ring is higher than that of the benzene ring, it is helpful to enhance the refractive index. ${ }^{34}$ Thus, the two non-coplanar pyridine rings of diazafluorene in dianhydride improved the refractive index of polyimides efficiently. Notably, the PI-1 film exhibited higher refractive index, which was attributed to a higher diazafluorene content of a polymer structure unit than that of PI-2, PI-3 and PI-4. Moreover, because the pyridine rings content of PI-4 was higher than that of PI-3, the refractive index of PI-4 was higher than that of PI-3. ${ }^{34,38}$ Based on these desirable properties, the polyimides could be used as potential candidates for applications in microelectronics.

\section{Conclusions}

A novel dianhydride monomer containing 4,5-diazofluorene was successfully synthesized and introduced into the polyimide backbone via polycondensation reaction of the dianhydride with different aromatic diamine monomers. The resulting polyimides exhibited excellent organo-solubility, good thermal stability and high $T_{\mathrm{g}}\left(270-311^{\circ} \mathrm{C}\right)$. The prepared polyimides displayed good mechanical properties and optical transparency, and low dielectric constant. In summary, the incorporation of 4,5-diazafluorene and ether bond units into the polyimide backbone leaded to a soluble high performance polyimide.

\section{Conflicts of interest}

There are no conflicts to declare.

\section{Acknowledgements}

The financial supports from the Science and Technology Project of Lanzhou (2016-3-62), the Fundamental Research Funds for the Central Universities (No. lzujbky-2016-ct05, lzujbky-2017114), and the Opening Foundation of PCFM lab of Sun Yatsen University are acknowledged. 


\section{References}

1 J. Dong, C. R. Yang, Y. Cheng, T. T. Wu, X. Zhao and Q. H. Zhang, J. Mater. Chem. C, 2017, 5, 2818.

2 H. J. Yen, J. H. Wu, Y. H. Huang, W. C. Wang, K. R. Lee and G. S. Liou, Polym. Chem., 2014, 5, 4219.

3 E. K. Chatzidaki, E. P. Favvas, S. K. Papageorgiou, N. K. Kanellopoulos and N. V. Theophilou, Eur. Polym. J., 2007, 43, 5010.

4 C. J. Chen, H. J. Yen, Y. C. Hu and G. S. Liou, J. Mater. Chem. C, 2013, 1, 7623.

5 D. Ren, H. L. Li, Y. Zhu and X. D. Bai, Polym. Adv. Technol., 2016, 27, 1642.

6 Y. W. Liu, C. Qian, L. J. Qu, Y. N. Wu, Y. Zhang, X. H. Wu, B. Zou, W. X. Chen, Z. Q. Chen, Z. G. Chi, S. W. Liu, X. D. Chen and J. R. Xu, Chem. Mater., 2015, 27, 6543.

7 L. T. T. Nguyen, H. N. Nguyen and T. H. T. La, Opt. Mater., 2007, 29, 610.

8 C. A. Terraza, L. H. Tagle, A. Tundidor-Camba, C. M. González-Henríquez, M. A. Sarabia-Vallejos and D. Coll, RSC Adv., 2016, 6, 49335.

9 Y. Liu, C. Gao, L. J. Xiao, Y. Xie, Y. Wang and W. Z. Li, RSC Adv., 2016, 6, 16404.

10 Z. X. Zhou, Y. Zhang, S. W. Liu, Z. G. Chi, X. D. Chen and J. R. Xu, J. Mater. Chem. C, 2016, 4, 10509.

11 S. Andre, F. Guida-Pietrasanta, A. Rousseau, B. Boutevin and G. Caporiccio, J. Polym. Sci., Part A: Polym. Chem., 2004, 42, 200.

12 Y. Zhou, G. F. Chen, W. Wang, L. H. Wei, Q. J. Zhang, L. P. Song and X. Z. Fang, RSC Adv., 2015, 5, 79207.

13 P. K. Tapaswi, M. C. Choi, Y. S. Jung, H. J. Cho, D. J. Seo and C. S. Ha, J. Polym. Sci., Part A: Polym. Chem., 2014, 52, 2316.

14 F. C. Yang, J. J. Zhao, Y. F. Li, S. J. Zhang, Y. Shao, H. Shao, T. Ma and C. L. Gong, Eur. Polym. J., 2009, 45, 2053.

15 Y. H. Zhang, P. Luo, H. Y. Yao and S. W. Guan, React. Funct. Polym., 2012, 72, 621.

16 S. Kumar Sen and S. Banerjee, RSC Adv., 2012, 2, 6274.

17 C. H. Chou, D. S. Reddy and C. F. Shu, J. Polym. Sci., Part A: Polym. Chem., 2002, 40, 3615.

18 Y. W. Liu, Y. Zhang, Q. Lan, S. W. Liu, Z. X. Qin, L. H. Chen, C. Y. Zhao, Z. G. Chi, J. R. Xu and J. Economy, Chem. Mater., 2012, 24, 1212.

19 Y. W. Liu, Y. Zhang, Q. Lan, Z. X. Qin, S. W. Liu, C. Y. Zhao, Z. G. Chi and J. R. Xu, J. Polym. Sci., Part A: Polym. Chem., 2012, 51, 1302.

20 W. X. Chen, Z. X. Zhou, T. T. Yang, R. X. Bei, Y. Zhang, S. W. Liu, Z. G. Chi, X. D. Chen and J. R. Xu, React. Funct. Polym., 2016, 108, 71.

21 C. L. Chung and S. H. Hsiao, Polymer, 2008, 49, 2476.
22 G. R. Newkome and C. D. Shreiner, Polymer, 2008, 49, 1.

23 S. Banerjee, G. Maier and M. Burger, Macromolecules, 1999, 32, 4279.

24 F. Li, W. J. Wan, J. C. Lai, F. Liu, H. X. Qi, X. S. Li and X. Z. You, J. Appl. Polym. Sci., 2015, 132, 7.

25 S. H. Hsiao and C. T. Li, J. Polym. Sci., Part A: Polym. Chem., 1999, 37, 1403.

26 S. J. Zhang, Y. F. Li, T. Ma, J. J. Zhao, X. Y. Xu, F. C. Yang and X. Y. Xiang, Polym. Chem., 2010, 1, 485.

27 S. Mehdipour-Ataei and Y. Nazari, J. Appl. Polym. Sci., 2012, 124, 2891.

28 R. Mercado, Y. Wang, T. Flaim, W. DiMenna and U. Senapati, Proc. SPIE, 2004, 5351, 276.

29 C. A. Terraza, J. G. Liu, Y. Nakamura, Y. Shibasaki, S. Ando and M. Ueda, J. Polym. Sci., Part A: Polym. Chem., 2008, 46, 1510.

30 Y. W. Liu, Z. X. Zhou, L. J. Qu, B. Zou, Z. Q. Chen, Y. Zhang, S. W. Liu, Z. G. Chi, X. D. Chen and J. R. Xu, Materials Chemistry Frontiers, 2016, 7, 17791.

31 X. L. Wang, Y. F. Li, C. L. Gong, S. J. Zhang and T. Ma, J. Appl. Polym. Sci., 2007, 104, 212.

32 H. J. Yen, C. L. Tsai, P. H. Wang, J. J. Lin and G. S. Liou, RSC Adv., 2013, 3, 17048.

33 X. H. Ma, B. Ghanem, O. Salines, E. Litwiller and I. Pinnau, ACS Macro Lett., 2015, 4, 231.

34 Y. Guan, D. M. Wang, Z. Wang, G. D. Dang, C. H. Chen, H. W. Zhou and X. G. Zhao, RSC Adv., 2014, 4, 50163.

35 Y. Mansoori, S. V. Atghia, S. S. Sanaei, M. R. Zamanloo, G. Imanzadeh and H. Eskandari, Polym. Int., 2012, 61, 1213.

36 X. L. Wang, Y. F. Li, S. J. Zhang, T. Ma, Y. Shao and X. Zhao, Eur. Polym. J., 2006, 42, 1229.

37 C. B. Wang, Y. Guan, D. B. Tian, G. D. Dang, D. M. Wang, C. H. Chen and H. W. Zhou, RSC Adv., 2015, 5, 103246.

38 H. Li, S. J. Zhang, C. L. Gong, Y. Liang, Z. G. Qi and Y. F. Li, Polym. Int., 2015, 64, 352.

39 H. Li, S. J. Zhang, C. L. Gong, Y. Liang, Z. G. Qi and Y. F. Li, Eur. Polym. J., 2014, 54, 128.

40 G. Hougham, G. Tesoro and J. Shaw, Macromolecules, 1994, 27, 3642 .

41 P. K. Tapaswi, M. C. Choi, K. Min Jeong, S. J. Ando and C. S. Ha, Macromolecules, 2015, 48, 3462.

42 G. Yang, R. Zhang, H. Huang, L. Liu, L. Wang and Y. Chen, RSC Adv., 2015, 5, 67574.

43 B. R. Bikson and Y. F. Freimanis, Vysokomol Soyedin., Ser., A, 1970, 12, 69.

44 S. Ando, T. Matsuura and S. Sasaki, Polym. J., 1997, 29, 69. 